\title{
Measles resurgence in Belgium from January to mid- April 2011: a preliminary report
}

M Sabbe (martine.sabbe@wiv-isp.be) ${ }^{1}$, D Hue ${ }^{1}$, V Hutse ${ }^{1}$, P Goubau ${ }^{2,3}$

1. Scientific Institute of Public Health, Brussels, Belgium

2. Department of Virology, Université Catholique de Louvain, Brussels, Belgium

3. National committee for the elimination of measles and rubella in Belgium

Citation style for this article:

Sabbe M, Hue D, Hutse V, Goubau P. Measles resurgence in Belgium from January to mid-April 2011: a preliminary report. Euro Surveill. 2011;16(16):pii=19848. Available online: http://www.eurosurveillance.org/ViewArticle.aspx?Articleld=19848

Article published on 21 April 2011

From 1 January to 14 April 2011, a total of 155 measles cases were notified in Belgium, whereas throughout 2010, there were only 40 . Of the 103 cases with known vaccination status, $87 \%$ had not been vaccinated with measles-mumps-rubella vaccine. The resurgence of measles is the consequence of insufficient vaccine coverage in previous years. Efforts to communicate the benefits of measles vaccination to the public and to advise health professionals on control measures and outbreak management are ongoing.

\section{Resurgence of measles in Belgium in 2011}

Since the beginning of 2011, Belgium has seen an increase in the number of measles cases. As of 14 April 2011, a total of 155 cases were reported through mandatory notification. In 2009 and 2010, only 33 and 40 cases, respectively, were reported. This in contrast to the period between April 2007 and May 2008, when a large measles outbreak, with more than 130 cases, occurred in Orthodox Jewish families in Belgium [1].

\section{Background}

Since 2003, paediatricians in a sentinel network surveillance system (PediSurv) and general practitioners in Belgium have recorded the number of measles cases [2]. Mandatory notification of the disease was adopted in the French-speaking community (in Wallonia) in 2006 and in the Flemish-speaking community (in Flanders) and in Brussels in 2009, as recommended in the national plan for elimination of measles and congenital rubella [3]. Physicians and microbiologists have to report suspected measles cases without delay to the regional health authorities or to PediSurv [2]. Laboratory confirmation is strongly recommended for sporadic cases, preferably by testing of oral fluid. Samples are sent to the Belgian National Reference Laboratory, where detection of measles virus-specific IgM and measles virus detection by PCR is carried out, as well as genotyping of the circulating viruses [4]. Notification forms are collected and analysed centrally at the Belgian Scientific Institute of Public Health.

Vaccination of measles-mumps-rubella (MMR) vaccine was introduced in Belgium in 1985 (one dose) and 1995 (two doses). The current measles vaccination strategy consists of two doses of MMR vaccine, the first at 12 months of age and the second between the age of 10 years and 13 years. Vaccination is free of charge and systematically offered through the childhood immunisation and school health programmes. Immunisation status is verified by childcare and public school services. If necessary, a catch-up dose is offered at the age of 5-7 years and 14-16 years. Despite these programmes, vaccination coverage of more than $95 \%$ with one dose of MMR vaccine - needed to meet the measles elimination goal for 2010 [5] - was reached in 2008 in only one of the three regions in Belgium (Flanders) (Table). Coverage of two MMR doses is lagging further behind. The coverage for children aged 18-24 months and second-year secondary school students (aged 14-16 years) is estimated in Flanders by a stratified multistage random sampling method; in Wallonia, a cluster sample survey method is used [6-8], The coverage shown in the Table is as reported by the communities, who are in charge of the vaccine programmes.

\section{Outbreak description}

Measles resurgence in Belgium this year began with an outbreak in anthroposophical schools in Ghent (Flanders) in February. A total of 56 children were affected - most of their parents were opposed to MMR vaccination. At the same time, outbreaks and sporadic cases were reported elsewhere in the country, especially in Brussels and Wallonia (Figure 1).These outbreaks often occurred after people had travelled to France, with spread of the measles virus to unvaccinated family members or pupils at school. Besides the outbreak in Ghent, we identified at least six small interfamilial outbreaks, two in schools and one in a Roma community. In 16 cases, an epidemiological link or recent ski trip to France was reported, and one case fell ill after travelling to Italy. In France, more than 3,700 measles cases were reported in January and February 2011 [9].

Virus transmission is still ongoing, with 151 cases reported in Belgium during January to March 2011, compared with five for the same period in 2010 (Figure 2). A further four cases were reported during 1 to 14 April 2011. 


\section{TABLE}

Vaccination coverage of measles-mumps-rubella vaccine in Belgium by region, 1995-2009a

\begin{tabular}{|c|c|c|c|c|c|c|c|c|}
\hline \multirow{2}{*}{ Region and MMR dose } & \multicolumn{8}{|c|}{ Percentage MMR vaccination coverage } \\
\hline & 1995 & 1999 & 2000 & 2003 & 2005 & 2006 & 2008 & 2009 \\
\hline \multicolumn{9}{|l|}{ Brussels } \\
\hline Second dose & - & - & - & - & - & 70.5 & - & - \\
\hline \multicolumn{9}{|l|}{ Flanders } \\
\hline First dose & - & 83.4 & - & - & 94.0 & - & 96.6 & - \\
\hline Second dose & - & - & - & - & 83.6 & - & 90.6 & - \\
\hline \multicolumn{9}{|l|}{ Wallonia } \\
\hline First dose & - & 82.4 & - & 82.5 & - & 89.0 & - & 92.4 \\
\hline Second dose & - & - & - & - & - & 70.5 & - & 75.5 \\
\hline
\end{tabular}

MMR: measles-mumps-rubella.

a Vaccine coverage as reported by the French-speaking and Flemish-speaking communities.

Source: [6-8].

\section{FIGURE 1}

Geographical distribution of measles cases in Belgium, January-March 2011 ( $\mathrm{n}=151)$

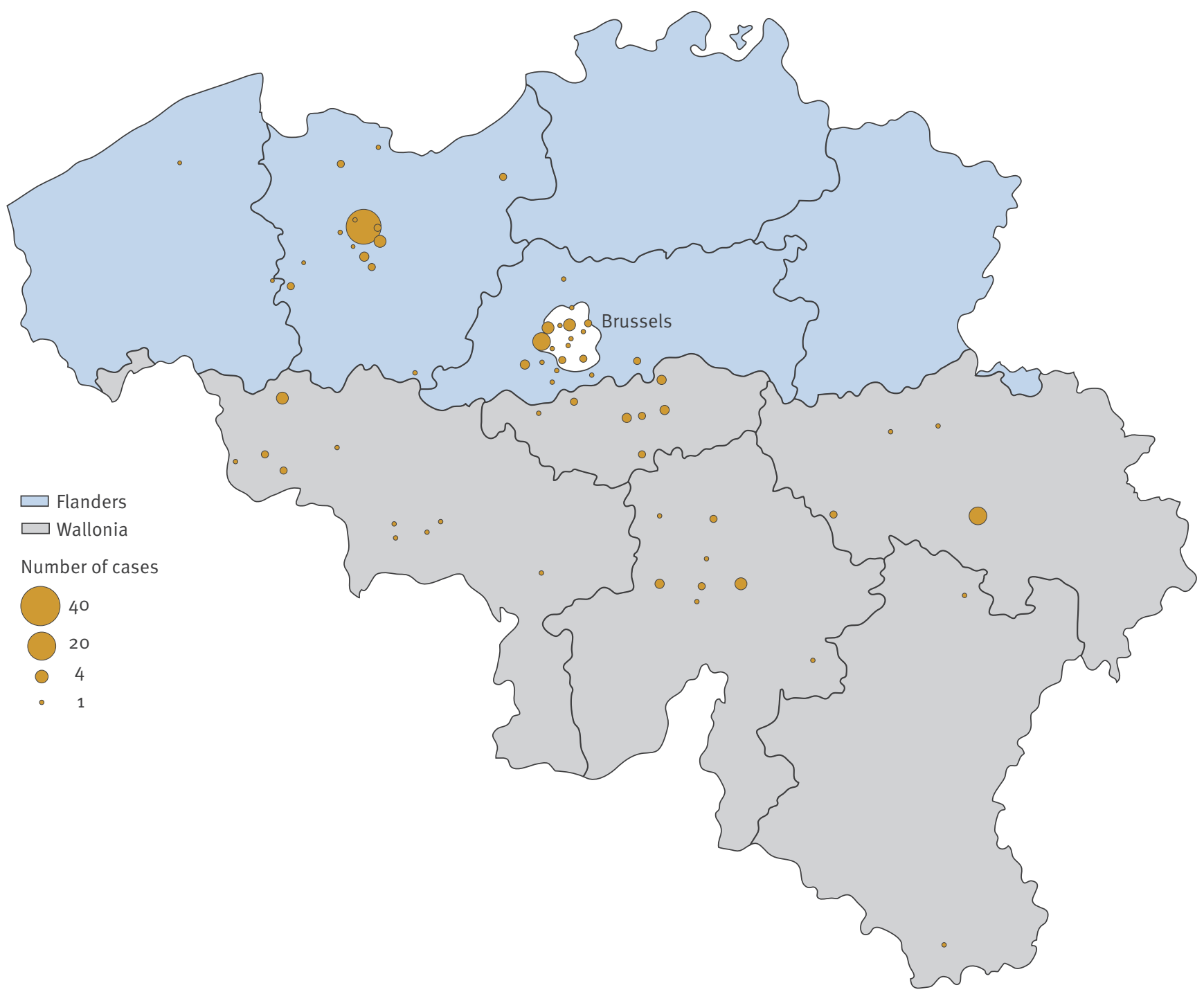

The internal lines represent the provinces. The dots represent the number of cases by municipality.

Source: Scientific Institute of Public Health, Brussels, Belgium. Preliminary data. 
Details of cases

Of the 155 Belgian cases identified between January and 14 April 2011, 147 had known date of birth and date of symptom onset. Their median age was nine years (range: 0-20 years). The median age of the cases not belonging to the outbreak in anthroposophical schools $(n=99)$ was 12 years (range: 0-49 years). One third of all the cases were aged 15 years or older (Figure 3).
Among the 12 cases aged less than one year, eight were laboratory confirmed. Four cases were younger than nine months.

Vaccination status was known for 103 cases (66\%). Of these, 90 had not been vaccinated with MMR vaccine. of the 13 vaccinated cases, all had received one dose

\section{FIGURE 2}

Reported measles cases, by month of symptom onset, Belgium, January 2007-March 2011

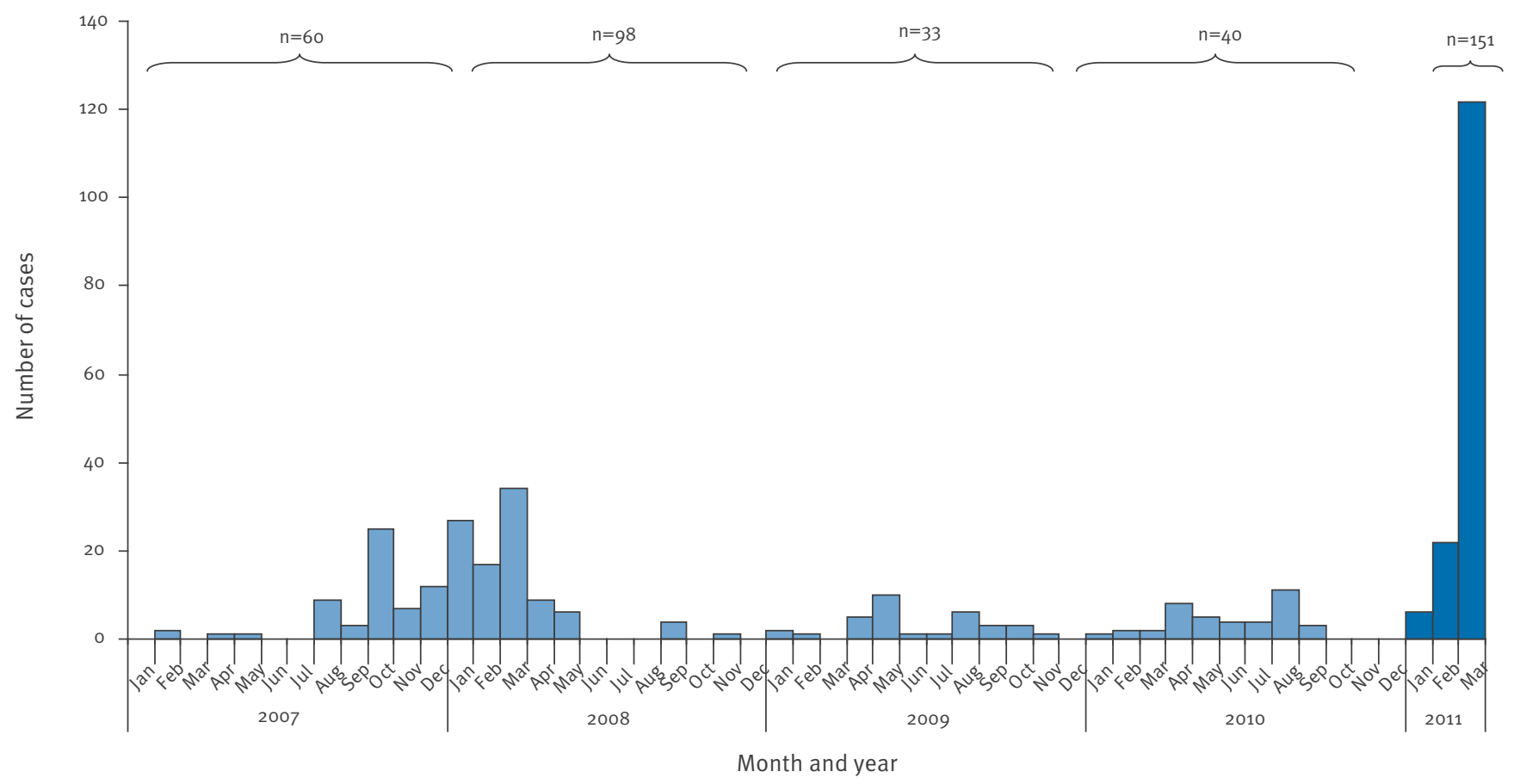

Source: Scientific Institute of Public Health, Brussels, Belgium. Preliminary data.

\section{FIGURE 3}

Reported measles cases with known date of birth, by age group, Belgium, 1 January 2008-14 April 2011

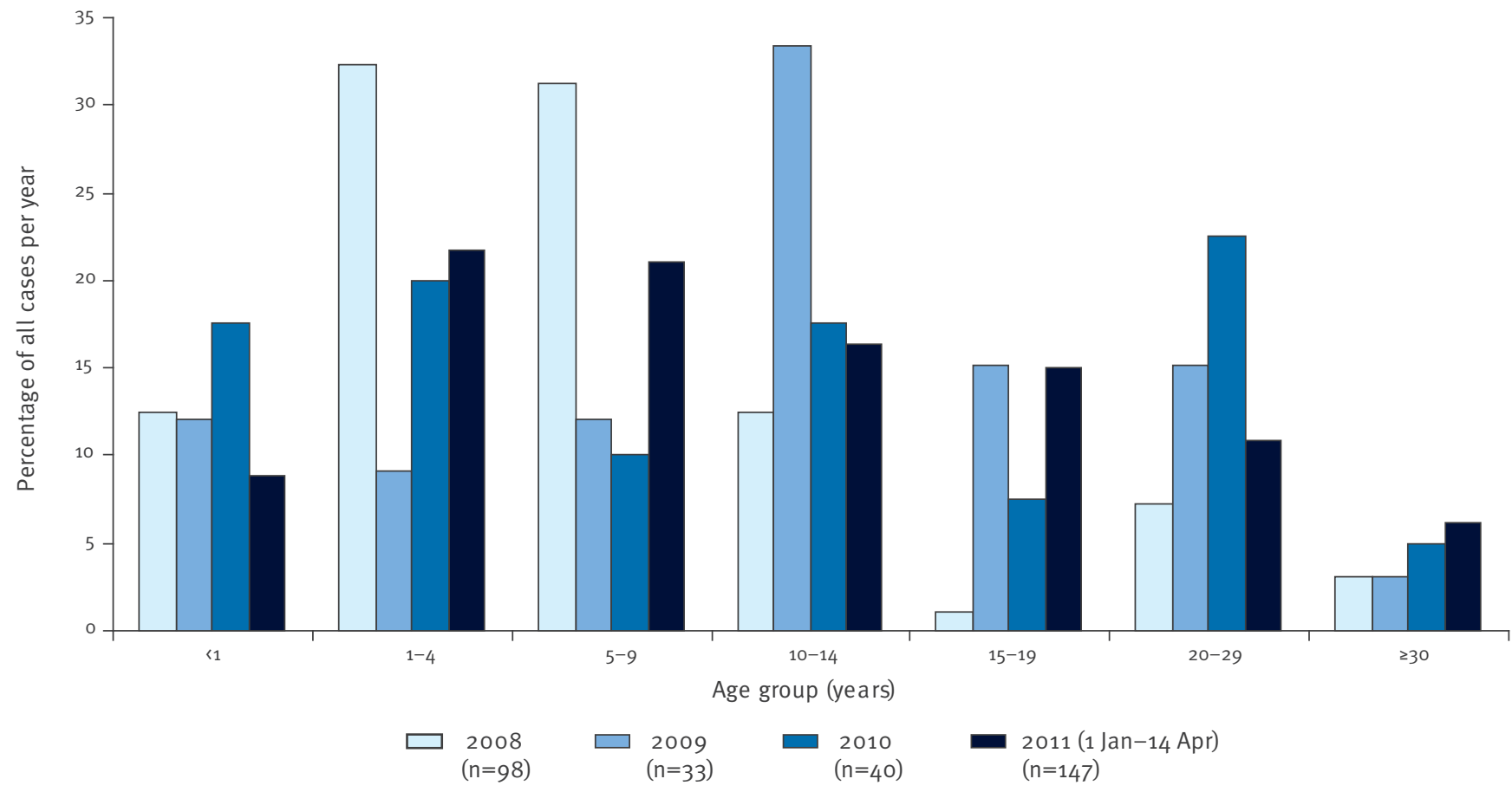

Source: Scientific Institute of Public Health, Brussels, Belgium. Preliminary data. 
of MMR vaccine (Figure 4), but sometimes this could not be verified on the vaccination chart. No recently vaccinated measles case was reported. In the cases older than one year, and thus old enough to be vaccinated, the main reasons for non-vaccination were their parents' anthroposophical beliefs ( $55 \%$ ), anti-vaccination counselling of the paediatrician resulting in parental refusal $(26 \%)$ or vaccination could not be carried out due to circumstances such as illness or travelling (13\%).

\section{Complications}

Hospitalisation was required for 19 patients. Seven cases were diagnosed with pulmonary complications: in one infant, this was followed by septic shock. One case of encephalitis occurred in a man in his late thirties. No deaths were reported.

\section{Laboratory results}

More than two thirds $(n=108)$ of the cases reported as of 14 April 2011 have been confirmed, either by detecting measles virus-specific IgM antibodies or viral RNA by reverse transcription-PCR (67 cases) or by an epidemiological link with a laboratory-confirmed case ( 41 cases). Preliminary results from the National Reference Laboratory showed that all viruses had genotype D4. However, two different subvariants of $\mathrm{D}_{4}$ were distinguished. The first subvariant strain MVs/Ghent. $\mathrm{BEL} / 09.11 / 1 /[\mathrm{D} 4]$, isolated during the outbreak in Ghent, is clearly related to MVs/Hamburg.DEU/03.09/ [D4]. A second subvariant strain, MVs/Brussels. BEL/08.11/[D4], detected in Wallonia, is indistinguishable from strains reported by reference laboratories in France (MVs/Paris.FRA/18.10/[D4]).

D4-Hamburg is a new strain of measles virus imported from London, United Kingdom, to Hamburg, Germany, in December 2008 [10]. D4-Hamburg has been present in Europe for more than two years and has led to more than 25,000 cases in 12 countries. Its spread was mainly but not exclusively associated with travelling Roma.

\section{FIGURE 4}

Known vaccination status of measles-mumps-rubella vaccine of measles cases by age group, Belgium,

1 January-14 April 2011, preliminary data $(n=103)$

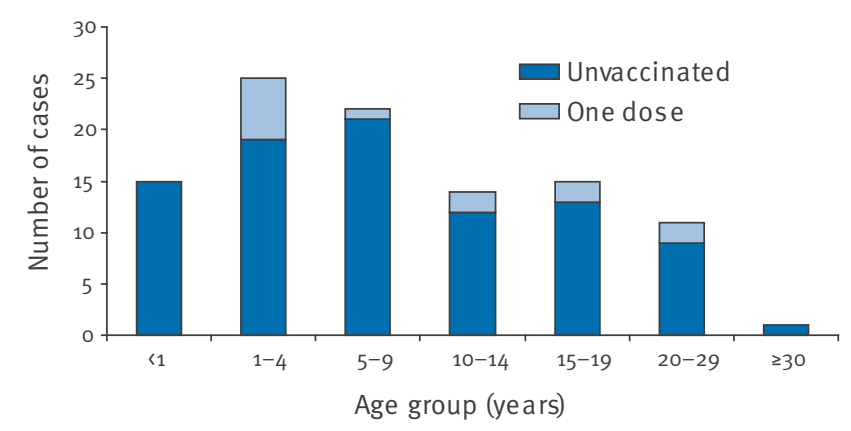

Source: Scientific Institute of Public Health, Brussels, Belgium. Preliminary data.

\section{Control measures}

Several control measures were implemented by local health authorities, according to the guidelines of the public health surveillance of the regions. Vaccination campaigns were organised in the anthroposophic schools in Ghent. Targeted information to health professionals and schools were sent. The national committee for the elimination of measles and rubella issued a press release, gave interviews on television and published articles in the press to inform the general public about the outbreaks and the need to be vaccinated. The main recommendations are for people to undergo vaccination according to the national immunisation schedule and to propose post-exposure vaccination, depending on age, time since exposure and existence of underlying diseases.

\section{Discussion}

Although measles incidence rate in 2009 was low, at 4 per $1,000,000$ population, it did not meet the measles virus elimination indicator of less than one measles case per 1,000,000 population [5]. This suggests that progress has been made in Belgium towards elimination, but the current measles resurgence is not unexpected, given the insufficient vaccination coverage of $M M R$ vaccine in Belgium in the past, allowing for silent accumulation of susceptible individuals. Current coverage, as reported by the French-speaking and Flemishspeaking communities, at 18-24 months of age with at least one dose is $92.4 \%$ in Wallonia and $96.6 \%$ in Flanders [6-8].

During outbreak investigations, several cases were identified who had not been notified to the local health authorities. This suggests that data available through the routine notification system underestimate measles incidence. Failure to notify such cases can be explained by no medical consultation for secondary cases in the same family plus insufficient knowledge or low motivation of some doctors regarding the notification procedure. The fact that measles only became mandatorily notifiable in 2009 for all the Belgian territory may also contribute to the underreporting.

The existence of groups with low measles vaccine coverage due to opposition to vaccination for religious or philosophical reasons or fear of side effects has been identified as one of the major barriers to achieve measles elimination in Europe [11]. In Belgium, anthroposophical schools, in which most of the children are unvaccinated, are mainly located in Flanders; only few are in Brussels and Wallonia. Other groups were affected by measles virus in Brussels and Wallonia for example. a Roma community and families opposed to vaccination due to fear of side effects. Patients attending medical practices in which attention is not paid to their vaccination status, presumably due to reluctance or negligence, can also play a role in low vaccination coverage.

This resurgence of measles in Belgium highlights the need to improve and maintain high vaccination 
coverage, along with disease surveillance and outbreak-control capabilities. Our findings also draw attention to the need to sensitise health professionals and raise their awareness of the issues through medical education. Convincing parents and health professionals reluctant to vaccinate children with MMR vaccine will be a challenge. Case investigation of every single measles case is a prerequisite to achieving the goal of measles elimination by 2015 , planned by the World Health Organization Regional Office for Europe [12].

\section{Acknowledgements}

The authors would like to thank all GPs and paediatricians of PediSurv, our colleagues from the local public health surveillances and the members of the national committee for the elimination of measles and rubella in Belgium.

References

1. Lernout T, Kissling E, Hutse V, De Schrijver K, Top G. An outbreak of measles in orthodox Jewish communities in Antwerp, Belgium, 2007-2008: different reasons for accumulation of susceptibles. Euro Surveill. 2009;14(2): pii=19087. Available from: http://www. eurosurveillance.org/ViewArticle.aspx?Articleld=19087

2. Sabbe M, Lernout T, Dupont Y, Quoilin S. The Belgian Paediatric Surveillance Unit "PediSurv": more than counting cases. Pediatr Infect Dis J. 2009;28(60):e73..

3. Sabbe M. Hue D. Elimination of measles and rubella in Belgium. Action plan 2009-2010. Report No.:D/2009/2505/008. Brussels: Institute of Public Health; 2009.

4. Hutse V, Van Hecke K, De Bruyn R, Samu O, Lernout T, Muyembe JJ, et al. Oral fluid for the serological and molecular diagnosis of measles. Int J Infect Dis. 2010;14(11):e991-7.

5. World Health Organization (WHO) Regional Office for Europe. Eliminating measles and rubella and preventing congenital rubella infection: WHO European Region strategic plan 20052010. Copenhagen: WHO Regional Office for Europe; 2005. Available from: http://www.euro.who.int/_data/assets/ pdf_file/ooo8/79028/E87772.pdf

6. Hoppenbrouwers K, Vandermeulen C, Roelants M, Boonen M, Van Damme P, Theeten $\mathrm{H}$, et al. Studie van de vaccinatiegraad bij jonge kinderen en adolescenten in Vlaanderen in 2008. 2009. Vaccine coverage survey in young children and adolescents in Flanders 2008. 2009 [Accessed 21 Apr 2011]. Flemish. Available from: http://www.google.co.uk/url?sa=t\& source $=$ web \& $c d=2 \&$ ved $=0 C B w Q F j A B \&$ url $=$ http $\% 3 A \% 2 F \% 2 F w$ ww.zorg-en-gezondheid.be $\% 2$ FWorkArea\%2Flinkit.aspx $\% 3$ FLin kIdentifier\%3Did\%26ItemID\%3D22784\&ei=EXKwTc-ilovUsga04 pT4Cw\&usg=AFQjCNHuyAcVSADPcKNH4F8mfh_eogg3vA

7. Robert E, Swennen B. Onderzoek naar de vaccinatietoestand van kinderen van 18 tot 24 maanden in het Brussels Hoofdstedelijk Gewest, december 2006. [Vaccine coverage study in chidren of 18 to 24 months in Brussels, December 2006]. ULB, Ecole de Santé Publique. [Accessed $21 \mathrm{Apr}$ 2011]. Flemish. Available from: http://www.observatbru.be/ documents/graphics/rapports-externes/onderzoek-naar-devaccinatietoestand-van-kinderen-van-18-tot-24-maanden-inhet-brussels-hoofdstedelijk-gewest.pdf

8. Robert E, Swennen B. Enquête de couverture vaccinale des enfants de 18 à 24 mois en communauté française (Bruxelles excepté). Novembre 2009. PROVAC-ULB; 2010. Vaccine coverage survey in children of 18 to 24 months in the French community (except Brussels). November 2009. PROVAC-ULB, Ecole de Santé Publique - ULB; 2010. [Accessed 21 Apr 2011]. French. Available from: http://www.sante.cfwb.be/fileadmin/ sites/dgs/upload/dgs_super_editor/dgs_editor/documents/ Publications/vacc/2009 CVac nourrissons.pdf

9. Institut de veille sanitaire (InVs). Epidémie de rougeole en France. Données de déclaration obligatoire en 2010 et données provisoires pour début 2011. [Measles outbreak in France. Data from mandatory reporting in 2010 and preliminary data for 2011]. Paris: InVs. [Accessed 21 Apr 2011]. [French]. Available from: http://www.invs.sante.fr/surveillance/rougeole/Point rougeole_220311.pdf
10. Mankertz A, Mihneva Z, Gold H, Baumgarte S, Baillot A, Helble $R$, et al. Spread of measles virus D4-Hamburg in Europe, 2008 2010. Emerg Infect Dis. Forthcoming.

11. Martin R, Deshevoi S, Buddha N, Jankovic D. Approaching measles and rubella elimination in the European region--need to sustain the gains. Euro Surveill. 2009;14(50): pii=19449. Available from: http://www.eurosurveillance.org/ViewArticle. aspx?Articleld=19449

12. World Health Organization (WHO). Regional Committee for Europe. Sixtieth session. Resolution. Renewed commitment to elimination of measles and rubella and prevention of congenital rubella syndrome by 2015 and Sustained support for polio-free status in the WHO European Region. EUR/RC60/ R12 . 16 September 2010. Available from: http://www.who.int/ immunization/sage/3_Resolution_EURO_RC6o_eRes12.pdf 